\title{
蓝田猿人动物䡛的性盾和时代
}

\author{
周 明 鎮 \\ （中国科学院古春椎动物与古人类研究所）
}

1963 年和 1964 年夏季，中国科学院古 春椎动物与古人类研究所篮田考察队，在傸 西蓝田县的陈家窝和公王岭两个地点, 先后 找到了猿人类型的人化石。根据吳汝康的初 步研究結果 ${ }^{[1]}$, 蓝田的人化石, 代表一种新 的猿人一一蓝田猿人 (Sinanthropus lantianensis Woo)。从头骨、下領骨和牙然的形态比 較,蓝田人比周口店的北京人显得較为原始, 时代也較早，因此蓝田猿人是目前我国发現 的最早的化石人类。这个发現，无疑在研究 人类的起源和进化史上有重大意义。

在蓝田陈家窝和公王岭两个猿人化石地 点, 和人类的遺䯓一起, 都发現有相当数量 的动物化石，根据这些共生的动物化石，可 以对蓝田猿人的时代和他們生活地区的自然 条件得到一些了解。

\section{一 公王蛉哺乳动物畫}

在公王岭猿人化石地点, 与猿人头盖骨 和上領骨一起发現的哺乳动物，經周明鎮、 胡长康、李玉清初步研究的結果 ${ }^{[2]}$, 計有 25 种，其中包括食肉类 11 种，奇嗳然 4

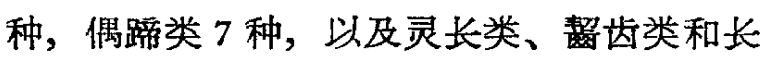
鼻类(象类)各 1 种。这些化石全部产于同一 个化石点 (63706 地点), 保存在更新統紅色
土层 (厚䄪 30 米) 近底部的含釾稹 結 核 层 中。化石地点及附近的地稹情况已由张玉 萍、黃万波等(1964)詳細报导 ${ }^{[3]}$ 。这个地点 经过 1963、1964 年的两个野外季度发掘, 除了哺乳类, 沒找到其它門类动物的化石。 化石保存得比較破碎, 材料主要是零散的牙 类、領骨和部分肢骨。

公王岭动物番包括的属和大部分种的名 单，以及在我国早、中更新世的时代分布如 表 1 所示。

表 1 所列的 25 种动物,其中大多数有足 够的材料作为代表, 特征很明显, 通过初步 鉴定可以肯定其所属的属、种; 另有一些种 类因标本不够或保存不好, 需要进一步研究 或根本无法鉴定。大角鹿和丽牛是两个新种。

\section{1. 公王岭动物摹的組成成分}

公王岭动物堡所表現的最明显的特色是

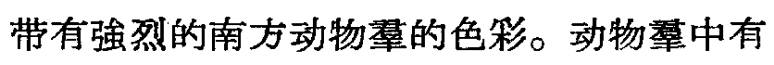
許多属, 如大猫熊 (Ailuropoda)、猎豹 (Acinony $x=$ Cynailurus)、剑齿象（Stegodon）、獏 (Tapirus)、爪兽 (Nestoritherium)、毛冠鹿 (Elaphodus)、水鹿 (Rusa) 等, 几乎都是过 去訩为在亚洲北部大陆上从中更新世起已經 絕灭的属, 而是我国南方及亚洲南部更新世 动物拳(如四川万县盐井沟)的主要成分。它 
表 1 公王朎蓝田猿人动物堡属、种的名单和时代分布

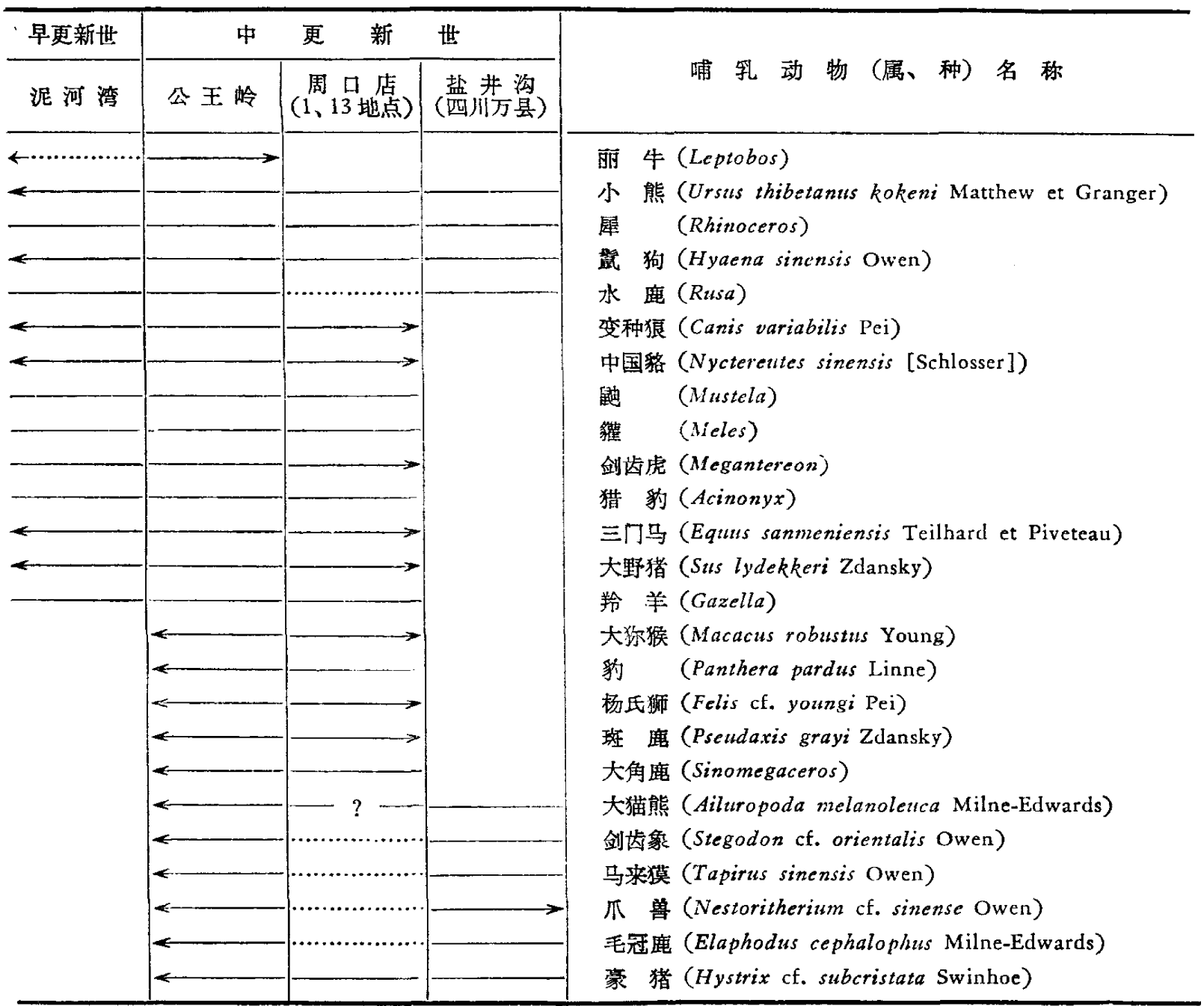

说明：表的橫线表示属、种分布的时代 (或层位), 虚线表示在该地点中未发现化石，但在同时代的其它地点出现。 箭头位置表示某一属、种地史分布的界限：左侧的箭头表示最早出现的时间，石侧的箭头表示最后出现 (灭绝)的时间。周口店和公王岭的大角鹿由不同的种为代表。公王岭的种显得较为原始。

們的分布在动物地理区划上都限于現代东洋 界所属的区域內。在目前关于公王岭动物萑 的資料还很不完全的情况下，这些动物的化 石在监田地区一起出現，显然至少包括三方 面的原因。首先，和我国北方已知的几个比 較典型的更新世地点比較, 监田的地理位置 比較偏近南方, 冬季( 1 月份)的平均温度比 北京至少高 $6^{\circ} \mathrm{C}$ 。在更新世某些时期, 当整 个华北的气候較温暖的时候，有一些热带或 亚热带动物的分布可以到达傸西南部地区。 其次一个原因可能是生态动物地理方面的,
监田在当时正位于秦岭北坡的亚热带栄林和 較北的森林草原与草原的交接地带(見后)， 因此在公王岭动物摹中有較多的南方的森林 性动物出現。再一点，显然是由于我們目前 对华北和西北第四紀哺乳类分布的情况，誩 識不足。除了周口店、泥河湾、薩拉烏苏等 少数几个“化石点”以外，我們对整个北方广 大地区的第四紀动物的了解还很不够。

与上述情况相对应, 公王岭动物莙雮与北 方其他相近的化石地点比較，缺少一些我国 北方常見的动物, 例如狐狸、大型的熊、駱 
駝、野牛等。这点从目前有限的資料还不能說 明是否有一定的动物地理和生态上的意义。

公王岭的动物的另一个特点是: 从現有 的化石名单看来，一方面动物萑中只有极少 数的属种是第三紀殘存种属(如剑齿虎)和第 四紀(更新世)早期的典型种属的代表（如丽 牛)。另一方面, 动物拏中現生种所占的百 分率很低 (至多不过 20\% 左右), 与北京猿 人地点(第一地点)比較，周口店动物杽中現 生种約占 $1 / 3$ 。这种差別除了可以訩为由于 公王岭地点的时代較早(見后)外，另一个很 重要的原因显然是因为目前知道的公王岭动 物萑的成分都是大型动物，小型动物則完全 缺失。因为更新世是哺乳类在历史上一个大 量絕灭的时期, 主要是受气候改变的影响, 而这种影响对大型动物要比对小动物显著。

公王岭动物堡中完全缺失水边生活或 “两栖性”的种类，如水獺、水牛、河狸等， 看来主要是与当地生态条件有关。此外, 采 集的标本中也几乎沒有小型动物（特別是繶 齿类) 和非剑齿象类的真象等一些更新統地 层中最常見的化石，这是由于目前資料太少 而造成的。

上述各种性貭表示，公王岭地点的动物 星代表一个过去在我国北方没有发現过的第 四紀哺乳动物䁷。这个动物蒘可以称为 “公 王岭动物荱”，或 “蓝田猿人动物藸”。它带 有很浓的南方或东洋动物界的色彩, 甚至蓝 由猿人本身也表示具有这种性稹。

\section{2. 公王岭动物薜的时代}

在确定一个化石动物蒘的地稹年代时， 主要是根据动物薭本身的組成和与有关动物 堡的对比。此外, 也可根据动物㳯中現生种 的百分率来推定, 不过在公王岭地点由于缺 失小型动物,故現生种的比率显著地过低(見
前), 因而不能作为确定时代的主要依据。

公王岭动物憵組成成分中，只有剑齿虎 和爪兽是較典型的第三紀的殘存代表。公王 岭发現的剑齿虎属（Megantereon），在亚洲 北部生存的时代，可以持續到周口店北京猿 人时期; 在亚洲南部发現于产早期爪姓猿人 化石的吉蒂斯 (Djetis) 层。爪兽类在我国北 方, 到周口店期时已經絕灭, 而公王岭中国 爪兽 (Nestoritherium sinense) 在我国南方中 更新世的动物蒘 (四川万县盐井沟) 中曾有 发現。因此这两个种, 都可以訩为是中更新 世的动物。另外，在国外(欧洲及亚洲南部) 和我国早更新世地点, 例如泥河湾 (河北 阳原), 周口店第 12、18 地点, 山西榆社、 临猗等，一些典型的早更新世的常見代表， 例如三趾馬、后爪兽 (Postschizotherium)、 板齿犀 (Elasmotherium)、多角鹿 (Euctenoceros）或 (Polycladus) 类的大型鹿类（如 Euctenoceros boulei) 和原始野牛 (Bison palaeosinensis), 以及其他一些亚种等級的动物, 在公王岭地点都没有发現。公王岭的 25 种哺 乳类中，有 13 个种 (約 $50 \%$ ) 在泥河湾中 都已出現，但这些种类在較晚的周口店动 物萑中仍然継續存在, 并有一些持續到現 代。

更重要的是，公王岭动物萍的 25 种动 物，有 11 种 (44\%) (例如豹、玟鹿、大角 鹿等), 在我国北方，都是在中更新世时第 一次出現的种（或属）。在确定一个动物堡 的地貭时代时，大量新类型的同时出現，比 古老种的存在更能作为一个新阶段开始的标 志，因而在确定时代上有更大的意义。公王 岭动物荱中，一方面缺之許多的早更新世的 典型属、种; 另一方面則有大量現代类型的 属、种出現，因此，公王岭哺乳动物鬼的时 
代，明显地具有中更新世动物惹的特色。

与我国主要的中更新世哺乳动物鋷比 較，公王岭动物拏和周口店北京猿人地点的 最为接近。周口店的中更新世动物毲，䒠要以 第 1 地点 (北京猿人化石地点) 和第 13 地点为 代表。这两个地点的实际差別只是：第 1 地 点的剖面較全, 而第 13 地点相当于第 1 地点 的下部，但有时被訩为系代表有上、下关系 的两个“化石层位”。从生物星的性稹看，两 者的化石組合应属于闰一个动物蒘。将周口 店第 1 和 13 地点与公王岭比較, 公王岭的 25 种动物中，至少有 17 种 (約 70\%)，在周口 店都有发現, 乎且有一些是比較常見和典型 的种，例如大雫猴、葛氏斑鹿、楊氏獅等， 根据过去的資料仅限于周口店第 $1 、 13$ 地 点, 或与这相近的层位。因此两者的时代显 然是比較接近的, 都具有华北中更新世哺乳 动物掱中一些典型的代表。

但是，根据現有的材料比較，公王岭动 物挈的一些性貭, 表現出和周口店北京猿人 动物䕷的性貭不相一致，公王岭动物堡中， 前面已提到，有許多种南方(“中国一馬来亚 动物拏”)的哺乳类，大都是在周口店沒有发 現过的。其次，有一些周口店常見的种类， 象大角鹿 (Sinomegaceros flabellatus, S. pachyosteus）在公王岭沒有发現，而由一个新种 为代表, 且显得比周口店的种更为原始。此 外, 在公王岭有一种丽牛 (Leptobos), 它的 时代主要是早更新世，只有在西欧和亚洲南 部个別地点, 可以到达中更新世早期 ${ }^{[4,5]}$ 。从 这些性貭看来, 公王岭地点的时代比周口店 第 1 和第13地点的早。公王岭的猿人化石代 表一种比北京猿人較为原始的猿人，也可以 作为这方面的一个証据。因此，蓝田动物挈 的时代,在地稹年表中应为中更新世的早期,
或第一间冰期(鄱阳大姑间冰期)。与国外对 比，大致相当于印尼爪哇的产早期爪哇猿人 或粗健猿人 (Homo erectus robustus) 化石的吉 蒂斯 (Djetis) 层。依照阿尔卑斯冰期的順序， 属于里茲一民德尔間冰期, 或克罗麦 (Cromerian）間水期；而周口店第 13 和第 1 地点的 时代为中更新世晚期，属于民德尔冰期（或 Mindel I/Mindel II Interstadial)，相当于爪哇 的特里尼尔层 (产晚期爪哇猿人 $H$. erectus erectus 的化石)。

\section{二 蓝田猿人陈家窝地点哺乳动物 覃的时代}

1963 年，在监田 陈 家窝与监田猿人下 頜骨化石一起，也发現过少量的哺乳动物化 石。經周明鎮 $(1964)^{[6]}$ 研究后，根据当时 发現的豹、虎、李氏野猪、斑鹿、方氏运鼠 等 6 种动物的性稹, 初步訩为动物茩的时代 为中更新世，大致和北京猿人的时代相当。 1964 年在同一地点又找到了一些化石，包 括几种腹足类的軟体动物和哺乳类动物。軟 体动物化石，据地貭科学研究院李云通同志 初步覌察，訩为基本上都是現代生活于华北 的种类。哺乳类中有一些是 1963 年沒有发現 过的。現在知道陈家窝动物鋷中, 至少有 14 个种。新发現的种类中，除大角鹿等大动物

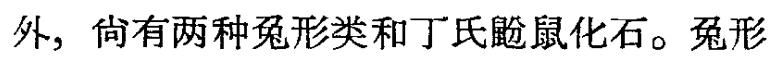
类中一种是勜氏免 (Lepus wongi), 过去只在 周口店(第 $1 、 13$ 地点)发現过; 另一是复齿 鼠峞 (Ochotonoides complicidens)，过去发現 于比周口店較早的地层中。丁氏邀鼠（Myospalax tingi) 的化石，时代一般也早于周口 店期。因此陈家窝地点的时代似比过去設想 的早，可能与公王岭的相当。两地发現有同 一种猿人的化石也表示出这种关系。 


\section{三 蓝田猿人生活的环境}

由于目前对化石地点地稹情况的了解还 不够，关于监田猿人时代当地的自然条件只 能根据哺乳动物荱性稹作几点初步推論。

公王岭动物恽中，种类最多的是森林动 物，如狋猴、虎、象、獏、野猪、毛冠鹿、 水鹿等。森林动物的属和种的数目占动物稗 的多数, 但大多只有少数另散标本为代表的 一、二个个体,化石保存不好。这些动物的殘 䯚可能是被水冲集在一起保存下来的。結合 当地的情况看, 都是生活在秦岭北側歪王岭 南坡森林中的种类。其次是草原动物, 如馬、 牛等, 种类虽不多, 但标本較多, 保存一般 也好得多，丽牛的材料(包括两个头骨), 至 少代表十余个个体。这些动物(包括羚羊、獅 和大角鹿(?)等)代表当时在公王岭附近草原 及森林草原中生活的种。陈家營新发現的材 料中, 如各种鼠类, 多数也是属于这一类葆 的动物。另外也有一些种, 如㪱狗、獾等对 环境則沒有严格的选择性。

另外，前面已提到，公王岭动物䖒中， 南方动物所占的比重超过我国北方中、晚更 新世任何一个动物䁷，有許多現代限于亚洲 南部热带和亚热带的动物的分布在当时达到 秦岭北側山地和西北黃土高原的南部。

上述情况表明, 监田猿人生存时期, 我 国北方的气候要比現代陝西南部和北京猿人 时期华北的气候要温暖。和我国北方更新世: 其他时期比較, 更接近于間冰期 (鄱阳大姑 间冰期 ) 的气候。

监田猿人的化石保存于夹在 “紅色士” (或紅色古黃土)中的一层古土壤中, 据朱显 谟研究认为这种古土壤层是 “在比較温暖和 稍湿潤的森林草原的生物气候条件下形成
的” [7]，与哺乳动物葆性稹所表示的情况相 一致。

\section{四 中国第四纪几个主要哺乳动物覃的颀序}

下面簡略地討論一下公王岭和其他几个 有关的动物摹, 特別是和人化石有关的动物 滓的时代和对比。

我国南方第四紀哺乳动物化石地点，可 以广西柳城、柳江，广东馬垻，以及四川万 县 (盐井沟)、資阳等为代表。巨猿 (Gigantopithecus）的时代,过去訩为和盐井沟动物 拏相当。解放后在广西柳城发現的大量化石 表明，巨猿不是这个动物苲的成員，而是属 于另一个时代較早的动物檴(“柳城”或“巨猿 动物摹”)。根据相应种(如大猫熊、剑齿象等) 的比較，巨猿的时代应早于公王岭动物萫， 可能是早更新世的后期 ${ }^{[8]}$ 。

以盐井沟为代表的所謂“中国一馬来亚” 或 “大猫熊一剑齿象动物堡” 的时代，过去 訩为和北方的周口店猿人地点相当。从許多 新資料看来，这是一相当复杂的 “动物葆 組合”，延續时間包括整个中、晚更新世， 只是由于华南在中、晚更新世时，自然环境 的变化不如北方显著, 对化石的研究也不 够，至今还不能根据化石組合区別出几个时 間上不同的层位，但是其中发現有不同阶段 的人类化石，如早期尼安德特人类型的馬垻 人、早期智人类型的柳江人, 以及可能更晚 一些的資阳人。我們虽然仍然可以用 “大猫 熊一剑齿象”或 “中国一馬来亚动物烇” 的名 称来泛指华南和亚洲南部邻接地区的中、晚 更新世动物免, 但为了免除混乱和便于对 比，最好把比較熟知和发現材料多的“盐井 沟地点”和华南其他地区（层位不肯定的）的

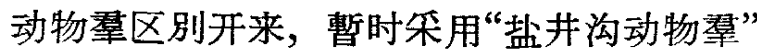


这一名詞代表一个中更新世晚期的化石层 位。它的时代显然晚于监田猿人动物蛘, 也可 能稍晚于周口店北京猿人地点的动物摹 ${ }^{[9]}$ 。

在北方，除周口店外，主要含人类化石 的哺乳动物萍是丁村 (山西襄汾)和薩拉烏苏 (河套)。丁村产人化石地点 (100 地点)所产 的峬乳类化石，几乎全部种类都是在薩拉烏 苏发現过的，因此时代不会早于晚更新世， 但从地层和石器交化的性稹上看来, 可能比 薩拉烏苏稍早。

与印尼爪哇猿人化石地点比較，在爪哇 有两个产猿人化石的层位: 下部吉蒂斯层和 上部特里尼尔 (Trinil) 层。吉蒂斯动物罋与
公王岭一样, 包括許多初次出現的現代哺乳 (如虎类、馬来獏等), 进步的丽牛属和早期 的直立猿人。因此，两者的时代可以对比， 而上部含晚期直立猿人的特里尼尔动物憵相 当于周口店北京猿人动物荱 ${ }^{[10,11]}$ 。

在亚洲其他地区，在日本的 Akiyoshi 地 区，曾发現有产大角鹿、东方剑齿象、楊氏 獅等化石的紅色粘土层 (Shikama and Okafuji, 1963) ${ }^{[121}$ 。这一地层 (Isa bed) 的动物摹的性 貭看来和公王岭很相似。

最后，我們可以将中国和印尼几个主要 更新世哺乳动物摹的順序与对比关系和人类 发展的主要阶段归納如下表:

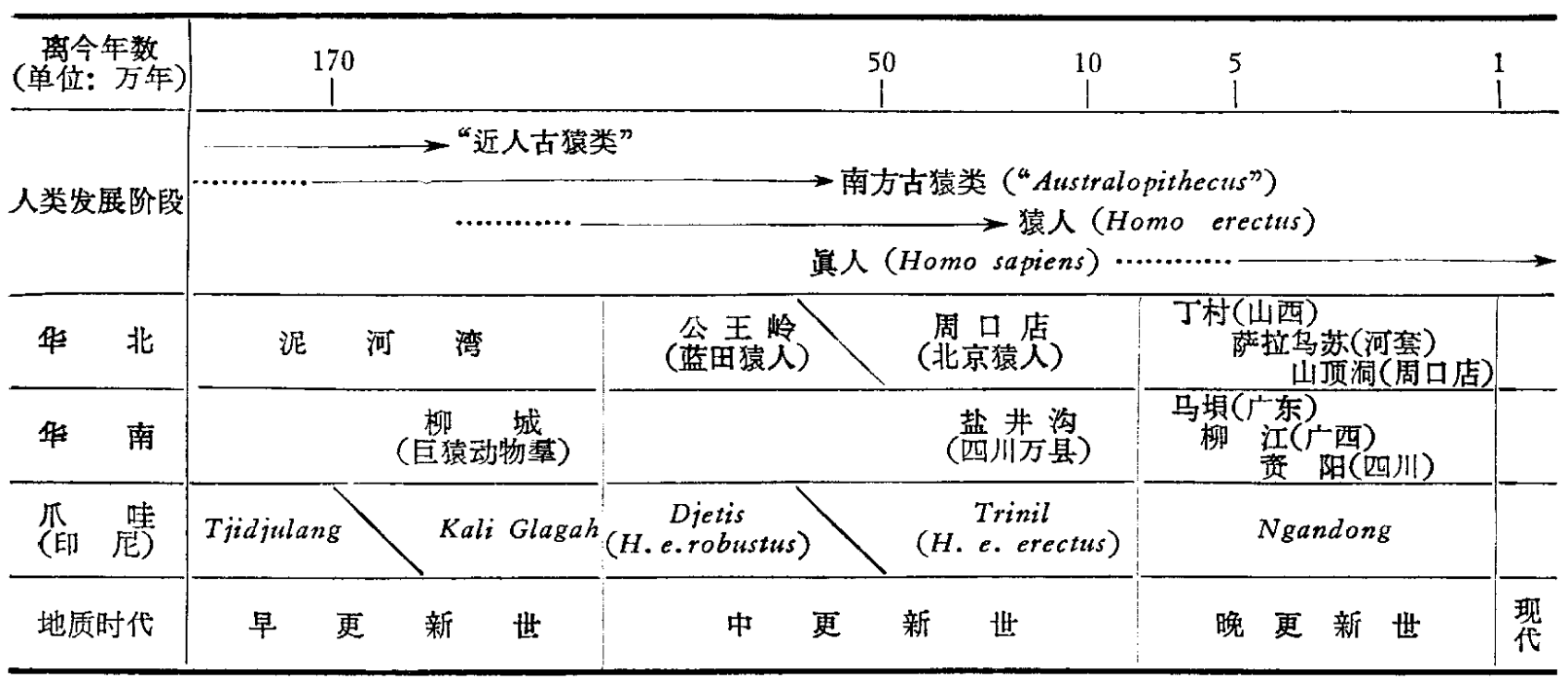

[1] 吳汝康, 古脊椎动物与古人类, 8[1], 1-17 (1964)。

[2] 周明镇、胡长康、李玉清, Scientia Sinica, XIV, No. 7,1965 。

[3] 张玉萍、黃万波等, 古脊椎动物与古人类, 8[2], 134-151 (1964)。

[4] Hooijer D. A., The Middle Pleistocene Fauna of Java, In G. Kurth: Evolution und Hominization, 108-111 (1962).

[5] Zeuner F. E., The Pleistocene Period, London, 1959.

[6] 周明镇, 古脊椎动物与古人类, 8[3], 301-311 (1964)。

[7]朱显谟, 中国黃土性沉积物中的古土壤, 中国第四 纪研究，4[1]，9-19 (1965)。

[8] 裴交中, 古脊栍动物与古人类, 6[3], 211一
218 (1962)。

[9] Kurten B., Soc. Scient. Fennica, Comment. Biol. 28[8], 1-12 (1960).

[10] Kahlke H. D., Zur relativen Chronologie ostasischer Mittelpleistozan-Faunen und HominoideaFunde. In G. Kurth: Evolution und Hominization, 84-107 (1963).

[11] von Koenigswald G. H. R., Das absolute Alter des Pithecanthropus erectus Dubois. Ibid., 112119 (1962).

[12] Shikama T. and Okafuji G., Yokohama Nat. Univ. Sci. Rep. Sec. II, 9, 51-58 (1963).

[13] Oakley K., Frameworks for Dating Fossil Man, London, 1964. 